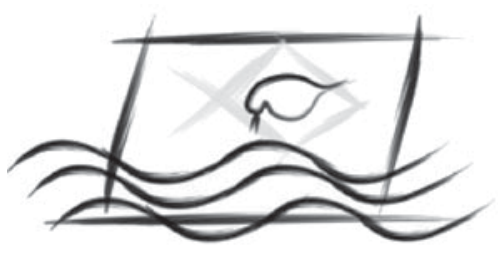

J. Braz. Soc. Ecotoxicol., v. 4, n. 1-3, 2009, 9-13

doi: 10.5132/jbse.2009.01.002

ECOTOX - Brazil

\title{
Sensibilidade de Algumas Espécies de Peixes de Água Doce Utilizadas no Brasil
}

\author{
E. BERTOLETTI ${ }^{*}$ \\ ${ }^{1}$ Setor de Ecotoxicologia Aquática, Companhia Ambiental do Estado de São Paulo - CETESB, São Paulo, Brasil
}

(Received August 11, 2008; Accepted November 30, 2009)

\begin{abstract}
RESUMO
Com a finalidade de comparar a sensibilidade de seis espécies de peixe de água doce, foram efetuados ensaios ecotoxicológicos, em condições idênticas, com os seguintes agentes químicos: cromo hexavalente, cobre, zinco, mercúrio, amônia não ionizada, e formulações dos praguicidas H.C.H. (popularmente B.H.C.) e D.D.T. As diferenças de sensibilidade foram consideradas expressivas quando a razão entre as CL(I) $50 ; 96 \mathrm{~h}$ foi $>2$. A normalização das CL(I) $50 ; 96 \mathrm{~h}$ permitiu ordenar a sensibilidade das espécies de peixes, indicando que as espécies nativas [Hemigrammus marginatus (bandeirinha) e Serrapinnus notomelas (piabinha)] possuem a mesma sensibilidade que as espécies tradicionalmente utilizadas [(Danio rerio (paulistinha) e Poecilia reticulata (guarú)]. As outras espécies exóticas, Cyprinus carpio (carpa comum) e Tilapia rendalli (tilápia), se mostraram menos sensíveis do que os demais peixes estudados. Este estudo permite concluir que espécies de peixes introduzidas, como o Danio rerio e Poecilia reticulata, podem substituir as espécies nativas de caracídeos nos ensaios de ecotoxicidade aguda com substâncias e efluentes líquidos.
\end{abstract}

Palavras-chave: ensaio ecotoxicológico, metais, peixes, sensibilidade, coeficiente de variação.

\section{ABSTRACT \\ Sensitivity of some freshwater fish species used in Brazil}

In order to compare the sensitivity of six freshwater fish species ecotoxicological assays were performed, under identical conditions, with the following chemicals: hexavalent chromium, copper, zinc, mercury, unionized ammonia, and pesticides formulations of H.C.H. and D.D.T. The differences in sensitivity were considered expressive when the ratio between 96 h-LC50s was $>2$. The normalized 96 h-LC50s allowed to order the sensitivity of fish species, indicating that native species [Hemigrammus marginatus (bandeirinha) and Serrapinnus notomelas (piabinha)] are as sensitivity as traditional species [(Danio rerio (zebrafish) and Poecilia reticulata (guppy)]. Other exotic species, such as Cyprinus carpio (common carp) and Tilapia rendalli (tilápia), showed less sensitivity than other species studied. This study indicates that species such as Danio rerio and Poecilia reticulata can be used as substitute of native species in acute ecotoxicity assays with chemicals and liquid effluents.

Keywords: ecotoxicological assay, fishes, metals, sensitivity, coefficient of variation. 


\section{INTRODUÇÃO}

Espécies de peixes nativas ou exóticas têm sido utilizadas, no Brasil, com a finalidade de avaliar a ecotoxicidade de agentes químicos específicos e efluentes líquidos. No entanto, a publicação de artigos completos sobre os efeitos tóxicos de poluentes em peixes é quase inexistente na revista brasileira especializada nesse assunto, isto é, no Journal of Brazilian Society of Ecotoxicology. Por outro lado, a análise dos resumos científicos publicados nos Congressos Brasileiros de Ecotoxicologia, de 1998 a 2008, revela que várias pesquisas efetuadas nesse período tratam dos efeitos tóxicos agudos direcionados para espécies de peixes de água doce, tanto nativas como exóticas, com a predominância do peixe Danio rerio.

Nessas publicações é possível verificar a recorrência da afirmação de que algumas espécies nativas de peixes são recomendadas para o uso em ensaios de ecotoxicidade aguda com base, tão somente, na obtenção da relação concentraçãoresposta de experimentos com certos agentes químicos. Além dessa impropriedade, é usual a comparação da sensibilidade da espécie de peixe estudada com outras espécies descritas na literatura, sem que haja uma análise crítica sobre as condições experimentais de ambas as pesquisas quanto à origem da água de diluição. Nesse sentido, embora a água de diluição possa apresentar dureza semelhante nos estudos confrontados, sua constituição pode tornar as comparações indevidas pela possibilidade das águas possuírem diferentes conteúdos de particulados ou de matéria orgânica, entre outros fatores. Assim, por exemplo, a especiação dos metais pode ser alterada em função da matéria orgânica presente e, consequentemente, pode haver diferenciação na intensidade do efeito tóxico desses agentes químicos.

Embora Domingues \& Bertoletti (2006) afirmem que o conhecimento da sensibilidade dos organismos, com base em uma diversidade de agentes químicos, é um dos princípios básicos para a escolha de uma espécie a ser utilizada nos ensaios ecotoxicológicos, tais autores não descrevem qualquer estudo sobre a sensibilidade dos peixes usados no Brasil. Portanto, o presente artigo tem o objetivo de demonstrar as concentrações letais medianas (em termos da CL(I) 50; 96 h) para espécies de peixes forrageiras e exóticas, com vários agentes químicos, sob condições idênticas quanto à qualidade da água de diluição, de modo a comparar a sensibilidade dos organismos de maneira inequívoca.

\section{MATERIAL E MÉTODOS}

Os resultados analíticos apresentados nesse artigo foram extraídos de CETESB (1979 e 1980), sendo que o número de ensaios consta nas Tabelas 2 e 3. Os ensaios com as espécies Danio rerio (paulistinha), Poecilia reticulata (guarú), Hemigrammus marginatus (bandeirinha) e Serrapinnus notomelas (piabinha) foram efetuados em sistema de fluxo contínuo de acordo com ABNT-NBR 12716 (1993). Os ensaios com as espécies Tilapia rendalli (tilápia) e Cyprinus carpio (carpa comum) foram efetuados em sistema semi-estático segundo a norma ABNT-NBR 15088 (2004). Os organismos da espécie Danio rerio foram originários do comercio local, enquanto os exemplares de Poecilia reticulata, Hemigrammus marginatus e Serrapinnus notomelas foram capturados em coletas de campo, sendo que Tilapia rendalli e Cyprinus carpio foram fornecidos por piscicultores especializados.

Em alguns dos ensaios foram utilizadas replicatas das soluções-teste, de modo a manter a relação de $1,0 \mathrm{~g}$ de peixe por litro de solução-teste. Alguns dados biométricos das espécies ensaiadas constam na Tabela 1.

A água de diluição utilizada nos ensaios foi a reconstituída, preparada com a adição de reagentes em água desmineralizada, conforme ABNT-NBR 15088 (2004). Em determinados experimentos utilizou-se a água de diluição moderadamente dura (dureza total $=100 \mathrm{mg} \mathrm{L}^{-1} \mathrm{em} \mathrm{CaCO}_{3}$ ) e em outros ensaios a água mole (dureza total $=40-48 \mathrm{mg} \mathrm{L}^{-1} \mathrm{em} \mathrm{CaCO}_{3}$ ).

Os seguintes agentes químicos, grau analítico, foram usados nos ensaios: dicromato de potássio $\left(\mathrm{K}_{2} \mathrm{Cr}_{2} \mathrm{O}_{7}\right)$, sulfato de cobre $\left(\mathrm{CuSO}_{4} 5 \mathrm{H}_{2} \mathrm{O}\right)$, sulfato de zinco $\left(\mathrm{ZnSO}_{4} 5 \mathrm{H}_{2} \mathrm{O}\right)$, cloreto de mercúrio $\left(\mathrm{HgCL}_{2}\right)$, cloreto de amônio $\left(\mathrm{NH}_{4} \mathrm{CL}\right)$, fenol $\left(\mathrm{C}_{6} \mathrm{H}_{5} \mathrm{OH}\right)$. Além desses, foram utilizados uma formulação comercial de D.D.T. (54\% do princípio ativo) da Hoechst, e uma formulação comercial de H.C.H. - Picapau (12\% do princípio ativo lindane).

Os teores de amônia não ionizada foram calculados com base na concentração nominal de nitrogênio amoniacal, segundo a fórmula abaixo estabelecida por Emerson et al. (1975):

porcentagem de amônia não ionizada $=\frac{1}{\left(10^{p K a-p H}+1\right)}$

em que:

$\mathrm{pKa}=$ constante de ionização em função da temperatura da solução (tabelada);

pH = potencial hidrogeniônico da solução-teste.

A análise estatística de Litchfield \& Wilcoxon (1949) foi empregada no cálculo das CL(I)50; 96 h. Para a comparação da sensibilidade relativa das espécies de peixe foi adotada a razão normalizada, ou seja, CL(I)50 do agente químico para uma determinada espécie $\div$ média das CL(I)50 do agente químico, calculada para o conjunto das espécies de peixe.

\section{RESULTADOS E DISCUSSÃO}

Antes de proceder à análise da sensibilidade das espécies, é importante que se estabeleça a base para a comparação das CL(I)50. Um dos modos para avaliar a sensibilidade dos

Tabela 1 - Biometria dos peixes utilizados nos ensaios.

\begin{tabular}{lcc}
\hline \multicolumn{1}{c}{ Espécie } & $\begin{array}{c}\text { Massa média } \\
(\mathrm{g})\end{array}$ & $\begin{array}{c}\text { Comprimento padrão } \\
(\mathrm{mm})\end{array}$ \\
\hline Danio rerio & 0,20 & 21,0 \\
Poecilia reticulata & 0,15 & 19,0 \\
Hemigrammus marginatus & 0,40 & 29,0 \\
Serrapinnus notomelas & 0,25 & 26,0 \\
Tilapia rendalli & 7,0 & 68,0 \\
Cyprinus carpio & 4,0 & $62,0^{*}$ \\
\hline
\end{tabular}

*comprimento furcal. 
organismos é a diferença estatística entre as CL(I)50 obtidas, conforme sugerido por Buratini \& Bertoletti (2006). No entanto, essa abordagem está fortemente influenciada pelas condições experimentais que podem refletir na amplitude dos intervalos de confiança e, conseqüentemente, no cálculo da significância das CL(I)50. Além disso, segundo Fogels \& Sprague (1977), a comparação estatística das CL(I)50 é limitada por não considerar a variabilidade dos métodos de ensaio com outras espécies e agentes químicos.

Alternativamente, as comparações da sensibilidade de organismos-teste são efetuadas com base na razão entre a maior e a menor CL(I)50 obtidas nos ensaios. Nessa comparação descritiva é possível considerar a variabilidade do método analítico envolvido, para cada espécie utilizada, o que torna as comparações mais abrangentes e precisas. Nesse sentido, com base na variabilidade dos ensaios ecotoxicológicos, Chapman (1983) sugere que a razão ao redor de 2 seja utilizada como uma medida de significância de outros parâmetros que afetam os resultados analíticos. Cumpre destacar que essa razão que está próxima ao coeficiente de variação (C.V.) $\leq 30 \%$ (razão estimada ao redor de 2,4) o qual é considerado razoável para qualquer método de ensaio ecotoxicológico (Environment Canadá, 1990). Outros estudos demonstram que a razão 2 é pertinente para as comparações de sensibilidade, visto que em série de ensaios de ecotoxicidade aguda com Danio rerio (Zagatto, 2006) o maior C.V. situou-se ao redor de $20 \%$ (razão estimada $=1,6$ ). Também, com essa espécie, Bertoletti et al. (1989) encontraram C.V. $=24 \%$ (razão verificada $=2,1$ ) para ensaios com uma formulação de D.D.T., enquanto no estudo de Kraus et al. (1998) o maior C.V. foi de $38 \%$ (razão verificada $=2,4$ ) em ensaios com cobre e Poecilia vivípara. Portanto, nesse trabalho, adotou-se a razão $>2$ para caracterizar a existência de diferenças expressivas na sensibilidade dos peixes estudados.
Assim, quando comparados os resultados dos ensaios com os dois tipos de água (Tabelas 2 e 3), verifica-se que as espécies $D$. rerio, $P$. reticulata e $H$. marginatus apresentam-se mais sensíveis ao cobre em água mole, com razões expressivas variando entre 2,9 e 4,6. Essas diferenças na sensibilidade eram previstas pela literatura sobre o assunto, sendo que na água mole esse metal tornou-se mais tóxico (Tabela 2), na mesma proporção demonstrada por Sprague (1985), especialmente por se tratar de água reconstituída em laboratório isenta de matéria orgânica. Ainda, em água mole o peixe Poecilia reticulata também apresentou maior sensibilidade para o mercúrio (razão $=2,3$ ), porém as condições experimentais e a literatura especializada não foram suficientes para elucidar essa ocorrência. Possivelmente, essa diferença nos resultados esteja associada à variabilidade analítica do ensaio com $P$. reticulata e o mercúrio.

Para a comparação da sensibilidade de um grupo de espécies de peixes é conveniente uma complementação no critério de avaliação. Nesse sentido, além da razão $\geq 2$, é necessário que os resultados sejam normalizados, à exemplo do estudo com as mesmas características efetuado por Slooff et al. (1983). Assim, no presente estudo, foi utilizada a razão normalizada, conforme demonstrado na Tabela 4. Desse modo, o uso de um denominador único, tal como a CL(I)50 média originária do grupo de espécies, permite integrar a comparação dos resultados analíticos, especialmente quando o grupo de espécies apresenta sensibilidade semelhante. Como conseqüência, a CL(I)50 média torna-se um ponto de referência que possibilita obter, proporcionalmente, razões menores para os organismos mais sensíveis e, também, razões maiores para aqueles mais resistentes.

Portanto, com base nas razões normalizadas, na Tabela 4 é apresentada a ordenação da sensibilidade relativa das espécies

Tabela 2 - Resultados dos ensaios ecotoxicológicos com peixes em água moderadamente dura (100 $\left.\mathrm{mg} \mathrm{L}^{-1} \mathrm{em} \mathrm{CaCO}_{3}\right)$.

\begin{tabular}{|c|c|c|c|c|c|}
\hline Espécie de peixe & & & $\mathrm{CL}(\mathrm{I}) 50 ; 96 \mathrm{~h}\left(\mathrm{em} \mathrm{mg} \cdot \mathrm{L}^{-1}\right)$ & & \\
\hline Agente químico & Danio rerio & Poecilia reticulata & Hemigrammus marginatus & Tilapia rendalli & Cyprinus carpio \\
\hline Cromo hexavalente & $45,5^{\mathrm{a}}$ & 60,0 & $41,2^{\mathrm{d}}$ & 38,7 & 111,7 \\
\hline Cobre & $0,12^{\mathrm{b}}$ & 0,08 & 0,13 & 0,92 & 0,14 \\
\hline Zinco & $22,0^{c}$ & 28,0 & 8,1 & - & - \\
\hline Mercúrio & 0,23 & 0,07 & $0,12^{\mathrm{d}}$ & 0,36 & 0,31 \\
\hline Amônia não ionizada & $1,85^{c}$ & 3,60 & 0,67 & - & 1,40 \\
\hline Fenol & $26,8^{\mathrm{a}}$ & 31,1 & $15,3^{\mathrm{b}}$ & 19,0 & 29,5 \\
\hline Formulação de H.C.H. & 5,6 & 2,9 & 3,4 & 83,2 & 165,7 \\
\hline
\end{tabular}

$\mathrm{a}=$ média de 10 ensaios, $\mathrm{b}=$ média de 11 ensaios, $\mathrm{c}=$ média de 8 ensaios, $\mathrm{d}=$ média de 2 ensaios.

Tabela 3 - Resultados dos ensaios ecotoxicológicos com peixes em água mole (40-48 $\mathrm{mg} \mathrm{L}^{-1} \mathrm{em} \mathrm{CaCO}_{3}$ ).

\begin{tabular}{|c|c|c|c|c|}
\hline \multirow{2}{*}{$\begin{array}{l}\text { Espécie de peixe } \\
\text { Agente químico }\end{array}$} & \multicolumn{4}{|c|}{$\mathrm{CL}(\mathrm{I}) 50 ; 96 \mathrm{~h}\left(\mathrm{em} \mathrm{mg} \mathrm{L}^{-1}\right)$} \\
\hline & Danio rerio & Poecilia reticulata & Hemigrammus marginatus & Serrapinnus notomelas \\
\hline Cromo hexavalente & 31,8 & 61,8 & 28,6 & 26,9 \\
\hline Cobre & 0,028 & 0,027 & 0,028 & 0,025 \\
\hline Mercúrio & 0,30 & 0,03 & 0,13 & 0,18 \\
\hline Amônia não ionizada & 1,30 & 1,80 & 0,46 & 0,93 \\
\hline Formulação de D.D.T. & 0,007 & 0,009 & 0,010 & 0,007 \\
\hline
\end{tabular}


de peixe comparadas no presente estudo. Nessa tabela, em termos absolutos, constata-se que todas as espécies apresentaram sensibilidade equivalente, isto é, com razão $<2,0$. No entanto, é possível verificar que o peixe forrageiro nativo Hemigrammus marginatus mostrou-se mais sensível em relação às outras espécies. Ao mesmo tempo as espécies Serrapinnus notomelas, Poecilia reticulata e Danio rerio mostram-se tão sensíveis quanto o Hemigrammus marginatus, com razão $\leq 1,7$. Por sua vez, as espécies Cyprinus carpio e Tilapia rendalli mostraram-se mais resistentes do que o Hemigrammus marginatus, com razão $\geq 2,6$, porém com mesma sensibilidade em relação às demais espécies (razão $\leq 1,9$ ). A menor sensibilidade de $C$. carpio e $T$. rendalli pode estar associada à maior massa corpórea desses peixes, conforme sugerido por Sprague (1985). Deve-se mencionar que a sensibilidade relativa permaneceu inalterada mesmo quando os dados normalizados foram calculados exclusivamente para cada tipo de água (moderadamente dura ou mole).

A pesquisa de Osti et al. (2007) confirma a sensibilidade de espécies semelhantes àquelas utilizadas no presente estudo. Embora esses autores tenham utilizado condições experimentais diferentes (exposição por 48 horas e cinco peixes/solução-teste), os mesmos demonstraram inexistir diferença significativa entre as médias das CL(I)50 de uma formulação do piretróide deltametrina para o caracídeo Hyphessobrycon bifasciatus e Danio rerio. Ao mesmo tempo, a formulação desse praguicida foi significativamente menos tóxica (razão > 7) para os ciclídeos Geophagus brasiliensis e Oreochromis niloticus.

A interpretação dos dados da Tabela 4 permite algumas inferências sobre a utilização de diferentes espécies de peixes no Brasil. Inicialmente, é possível constatar que espécies as espécies de peixe forrageiras nativas (Hemigrammus marginatus e Serrapinnus notomelas), pertencentes à família mais abundante em águas doces brasileiras, os caracídeos, possuem a mesma

Tabela 4 - Sensibilidade relativa normalizada das espécies de peixes estudadas, considerando todos os resultados e tipos de água.

\begin{tabular}{lc}
\hline \multicolumn{1}{c}{$\begin{array}{c}\text { Espécies de peixe } \\
(\mathrm{n}=\text { número de normalizações })\end{array}$} & $\begin{array}{c}\text { Média das razões } \\
\text { normalizadas* }\end{array}$ \\
\hline Hemigrammus marginatus $(\mathrm{n}=12)$ & 0,6 \\
Serrapinnus notomelas $(\mathrm{n}=5)$ & 0,9 \\
Danio rerio $(\mathrm{n}=12)$ & 0,9 \\
Poecilia reticulata $(\mathrm{n}=12)$ & 1,0 \\
Cyprinus carpio $(\mathrm{n}=6)$ & 1,6 \\
Tilapia rendalli $(\mathrm{n}=5)$ & 1,7 \\
\hline
\end{tabular}

* razão normalizada $=$ CL(I)50 do agente químico para uma determinada espécie $\div$ média das CL(I)50 do agente químico calculada para o conjunto das espécies de peixe.

Tabela 5 - Correlação da sensibilidade entre espécies de peixes selecionadas.

\begin{tabular}{lcccc}
\hline \multicolumn{1}{c}{ Correlação } & $\mathrm{n}$ & Equação da reta & $\mathrm{r}^{*}$ & $p^{* *}$ \\
\hline H. marginatus $(\mathrm{Hm})$ & 8 & $\log \mathrm{CL}(\mathrm{I}) 50 \mathrm{Hm}=-0,19+$ & 0,98 & $<0,0001$ \\
e D. rerio $(\mathrm{Dr})$ & & $0,92 \times \log \mathrm{CL}(\mathrm{I}) 50 \mathrm{Dr}$ & & \\
H. marginatus $(\mathrm{Hm})$ & 8 & $\log \mathrm{CL}(\mathrm{I}) 50 \mathrm{Hm}=-0,11+$ & 0,95 & $<0,0001$ \\
e $P$. reticulata $(\mathrm{Pr})$ & & $0,82 \times \log \mathrm{CL}(\mathrm{I}) 50 \mathrm{Pr}$ & & \\
\hline * coeficiente de determinação, * *nível de significância. &
\end{tabular}

*coeficiente de determinação, **nível de significância. sensibilidade daquelas espécies recomendadas internacionalmente para os ensaios ecotoxicológicos (Danio rerio e Poecilia reticulata). Essa constatação possibilita evitar a captura de espécies nativas, em ambientes naturais, com a finalidade de uso em ensaios ecotoxicológicos, visto que dificilmente são cultivadas em laboratório ou possuem reprodução sazonal. Por outro lado, as espécies Danio rerio e Poecilia reticulata podem ser utilizadas rotineiramente, tanto pela sensibilidade equivalente como pela facilidade de cultivo, além da reprodução contínua ao longo do ano.

A análise de regressão, pelo método dos mínimos quadrados, consiste em outra forma de comprovar a proximidade dos resultados entre a espécie nativa mais sensível e aquelas usualmente recomendadas em métodos padronizados. Na Tabela 5 constam as correlações encontradas com todos os pares de dados da Tabela 3 e os dados pareados do zinco, fenol e formulação de H.C.H. da Tabela 2. Tendo em vista que a inclinação das retas é $\geq 0,82$, as equações demonstram que a sensibilidade das espécies está muito próxima. Portanto, é possível estimar, com razoável precisão, a intensidade do efeito tóxico de um agente químico (substância ou efluente) para a espécie Hemigrammus marginatus com base na CL(I)50 determinada para Danio rerio ou Poecilia reticulata.

A sensibilidade das espécies Hemigrammus marginatus e Serrapinnus notomelas pode ser extrapolada para outros caracídeos forrageiros. Essa afirmação se justifica, pois Stephan et al. (1983) quando estabeleceram critérios numéricos de qualidade de águas para proteção da vida aquática os E.U.A. notaram que, em média, espécies de organismos dentro de famílias são toxicologicamente muito mais semelhantes do que entre famílias diferentes. Em outros estudos, Leblanc (1984) e Suter et al. (1985) demonstraram que, com ampla base de dados de ecotoxicidade aguda, as correlações de sensibilidade entre as espécies declinam com o aumento da distância taxonômica. Suter et al. (1985) ainda evidenciaram que a sensibilidade dos gêneros dentro de famílias foi similar àquela para espécies dentro dos gêneros. Tais evidências sugerem que outros caracídeos possuem a mesma sensibilidade daqueles utilizados no presente trabalho, fato que prescinde a necessidade de futuras pesquisas com outras espécies dessa família de peixe.

Outro aspecto que merece destaque é o estigma da falta de sensibilidade do peixe Poecilia reticulata aos agentes químicos, especialmente no Brasil. Talvez a observância dessa espécie de peixe em águas com baixo teor de oxigênio dissolvido, proporcionada pela sua estrutura bucal que permite a captação de oxigênio na lâmina d'água, seja a causa do julgamento equivocado. $\mathrm{O}$ presente trabalho ratifica aquele primordial efetuado por Pickering \& Henderson (1966), que demonstrou Poecilia reticulata ter a mesma sensibilidade que outras espécies de peixes de águas doces sub-tropicais.

Portanto, com base em ensaios ecotoxicológicos com agentes químicos diferenciados, conclui-se que espécies de peixes introduzidas, como o Danio rerio e Poecilia reticulata, podem substituir as espécies nativas de caracídeos nos ensaios de ecotoxicidade aguda com substâncias ou efluentes líquidos. 


\section{REFERÊNCIAS BIBLIOGRAFICAS}

ABNT (ASSOCIAÇÃO BRASILEIRA DE NORMAS TÉCNICAS). 1993. Água - Ensaio de toxicidade aguda com peixes - Parte III - Sistema de fluxo contínuo. $17 \mathrm{p}$.

ABNT (ASSOCIAÇÃO BRASILEIRADE NORMAS TÉCNICAS). 2004. Ecotoxicologia aquática - Toxicidade aguda - Método de ensaio com peixes - 19p.

BERTOLETTI, E., GHERARDI-GOLDSTEIN, E. \& ZAGATTO, P.A., 1989. Variabilidade de testes de toxicidade com peixes. Ambiente, 3 (1):52-58.

CETESB. 1979. Programa Bioensaios. Relatório final anual-1979. CETESB, São Paulo. Relatório Técnico. Vol. I e II. 508p.

CETESB. 1980. Programa Bioensaios. Relatório de atividades 1980. CETESB, São Paulo. Relatório técnico. 55p. e anexos.

CHAPMAN, G. A. 1983. Do organisms in laboratory tests respond like organisms in nature? In: Bishop, W.E.; Cardwell, R.D.; Heidolph, B.B. (Eds). Aquatic Toxicology and Hazard Assessment: Sixth Symposium. STP 802. Philadelphia, ASTM., p. 315-327.

DOMINGUES, D.F. \& BERTOLETTI, E. 2006. Seleção, manutenção e cultivo de organismos aquáticos. In: Zagatto, P.A. \& Bertoletti, E. (eds), Ecotoxicologia aquática: Princípios e aplicações. São Carlos. RIMA. p.153-184.

EMERSON, K,; RUSSO, R.C.; LIND, R.E. \& THURSTON, R.V., 1975. Aqueous ammonia equilibrium calculations: effect of $\mathrm{pH}$ and temperature. J.Fish.Res.Board Can. 32 : 2379-2383.

FOGELS, A. \& SPRAGUE, JB. 1977. Comparative short-term tolerance of zebrafish, flagfish, and rainbow trout to five poisons including potencial reference toxicants. Water Res.11: 811-817.

KRAUS, L.A.S., BONECKER, A.C.T. \& VITAL, N.A.A. 1998. Acute toxicity of potassium dichromate, sodium dodecyl sulfate, copper and zinc to Poecilia vivipara (Osteichthyes, Cyprinodontiformes). Fresenius Envir.Bull. 7: 654-658.
LEBLANC, G.A., 1984. Interspecies relationships in acute toxicity of chemicals to aquatic organisms. Environ.Toxicol.Chem. 3 : 47-60.

LITCHFIELD Jr, J.T. \& WILCOXON, F., 1949. A simplified method of evaluating dose- effect experiments. Journal of Pharmacology and Experimental Therapeutics, 96: 99-113.

OSTI, S.C.; VAROLI, F.M.F.; MATUSHIMA, E.R. \& BERNARDI, M.M., 2007. Comparative studies of delthametrin acute toxicity in exotic and Brazilian fish. J.Bras.Soc.Ecotoxicol. 2 (2): 101-106.

PICKERING, Q.H \& HENDERSON, C. 1966. The acute toxicity of some heavy metals to different species of warmwater fishes. Air Wat.Pollut.Int.Journal 10 : 453-463.

SLOOFF, W., CANTON, J.H. \& HERMENS, J.L.M.. 1983. Comparison of the susceptibility of 22 freshwater species to 15 chemicals compounds. I. (sub)acute toxicity tests. Aquatic. Toxicol. 4 : 113-128.

SPRAGUE, J.B. 1985. Factors that modify toxicity. In: Rand, G.M. \& Petrocelli, S.R. (eds), Fundamentals of Aquatic Toxicology: Methods and applications. Washington, Hemisphere Pub. Co. p. 124-163.

STEPHAN, C.E., MOUNT, D.I., HANSEN, D.J., GENTILE, J.H., CHAPMAN, G.A. \& BRUNGS, W.A., 1983. Guidelines for deriving numerical national water quality criteria for protection of aquatic life and its uses. Draft (July, 5) U.S.EPA. 83 p.

SUTER, G.W., BARNTHOUSE, L.W., BRECK, J.E., GARDNER, R.H. \& O'NEILL, R.V., 1985. Extrapolating from the laboratory to the field: how uncertain are you? In: Cardwell. R.D.; Purdy, R. e Bahner, R.C. (eds). Aquatic Toxicology and Hazard Assessment: Seventh Symposium - STP 854. Philadelphia. ASTM. p. 400-413.

ZAGATTO, P.A. 2006. O uso de substâncias de referência no controle de qualidade de ensaios ecotoxicológicos. In: Zagatto, P.A. \& Bertoletti, E. (eds), Ecotoxicologia aquática: Princípios e aplicações. São Carlos. RIMA. p.185-197. 
